\title{
STUDI KUALITAS DAN PENETAPAN DAYA TAMPUNG BEBAN PENCEMARAN SUNGAI BATANG KURANJI
}

\author{
Erna Juita \\ Program Studi Pendidikan Geografi STKIP PGRI Sumatera Barat \\ Email: erna.pgri@gmail.com
}

\begin{abstract}
Pollution of water will have an impact on the ecological aspects, social, cultural and economical too. Thus the effort necessary improvements and countermeasures against polluted river costly when compared with the benefits derived from the river. One of the environmental problems that arise in the city of Padang was pollution in some rivers. This causes a decrease in the quality of river water, while known to the river is a source of water that is still used by people who live along the river flow. But on the other side of the river is one of the shelters of waste water or waste originating from a variety of activities such as residential population, household industry and market. Padang city, there are several rivers flowing along the residential areas in between Sungai Batang Arau, Batang Kandis, Batang Kuranji and others. Therefore, the quality of the river should be maintained so communities along the river can exploit. Capacity calculation is done on the river Batang Kuranji divided by five (5) sections calculations. These considerations are based on the same type of pollutant sources resulting in decreased water quality Kuranji Batang River, their tributaries were in and out of Sungai Batang Kuranji.
\end{abstract}

Keywords: Quality, Capacity, Pollution

\begin{abstract}
Abstrak
Pencemaran terhadap perairan akan berdampak pada aspek ekologis, social, budaya dan juga ekonomis. Sehingga dengan demikian upaya perbaikan dan penanggulangan yang diperlukan terhadap sungai yang tercemar membutuhkan biaya yang besar bila dibandingkan dengan manfaat yang diperoleh dari sungai tersebut. Salah satu permasalahan lingkungan yang muncul di Kota Padang adalah pencemaran pada beberapa sungai. Hal ini menyebabkan penurunan kualitas air sungai, sementara diketahui sungai merupakan sumber air yang masih dimanfaatkan oleh masyarakat yang berada di sepanjang aliran sungai tersebut. Namun dilain pihak sungai merupakan salah satu tempat penampungan air buangan atau limbah yang berasal dari berbagai kegiatan seperti perumahan penduduk, industry rumah tangga, dan pasar. Kota Padang terdapat beberapa sungai yang mengalir di sepanjang pemukiman penduduk di antaranya Sungai Batang Arau, Batang Kandis, Batang Kuranji dan lainnya. Oleh sebab itu kualitas sungai tersebut perlu dijaga agar masyarakat di sepanjang aliran sungai dapat memanfaatkannya. Perhitungan daya tampung yang dilakukan pada sungai Batang Kuranji dibagi 5 (lima) bagian perhitungan. Pertimbangan ini berdasarkan atas jenis yang sama, sumber pencemar yang mengakibatkan penurunan kualitas air Sungai Batang Kuranji, adanya anak sungai yang masuk dan keluar dari Sungai Batang Kuranji.
\end{abstract}

Kata Kunci:Kualitas, Daya Tampung, Pencemaran 


\section{PENDAHULUAN}

Air merupakan sumber daya alam yang dibutuhkan untuk memenuhi hajat hidup orang banyak, sehingga perlu dilindungi agar dapat tetap bermanfaat bagi kehidupan manusia serta makhluk hidup lainnya. Untuk menjaga kualitas air pada kondisi alamiah agar dapat dimanfaatkan secara berkelanjutan sesuai dengan tingkat mutu air yang diinginkan, perlu adanya upaya pelestarian dan pengendalian.Pelestarian kualitas air dilakukan pada sumber air yang terdapat di hutan lindung. Sedangkan kualitas air dilakukan pada sumber air, yang terdapat badan air penerima dengan upaya pengendalian pencemaran air. Upaya tersebut untuk memelihara fungsi air agar kualitasnya memenuhi baku mutu air yang ditetapkan.

Sehubungan dengan diberlakukan Undang-Undang Otonomi Daerah termasuk perangkat peraturan yang mengikutinya, kewenangan Pemerintah Kabupaten / Kota serta Propinsi menjadi sangat kuat untuk melakukan pengaturan di wilayah administrasinya. Selain itu, kewajibannya yang terkandung dalam PP No. 82/2001 tentang pengelolaan kualitas air dan pengendalian pencemaran air, pemerintah daerah diharuskan untuk melakukan inventarisasi sumber daya air, penilaian status mutu air dan penetapan daya tampung beban pencemaran air (DTBPA) untuk seluruh sungai termasuk anak sungai.

Pengelolaan kualitas air dalam Perda No. 3/2004 adalah upaya pemeliharaan air sehingga tercapai kualitas air yang diinginkan, sesuai dengan peruntukannya untuk menjamin agar kualitas air tetap dalam kondisi baik. Sedangkan pengendalian pencemaran air adalah upaya pencegahan dan penanggulangn pencemaran air, serta pemulihan kualitas air, agar sesuai dengan baku mutu air.

Pencemaran terhadap perairan akan berdampak pada aspek ekologis, social, budaya dan juga ekonomis. Sehingga dengan demikian upaya 
perbaikan dan penanggulangan yang diperlukan terhadap sungai yang tercemar membutuhkan biaya yang besar bila dibandingkan dengan manfaat yang diperoleh dari sungai tersebut.

Salah satu permasalahan lingkungan yang muncul di Kota Padang adalah pencemaran pada beberapa sungai. Hal ini menyebabkan penurunan kualitas air sungai, sementara diketahui sungai merupakan sumber air yang masih dimanfaatkan oleh masyarakat yang berada di sepanjang aliran sungai tersebut. Namun dilain pihak sungai merupakan salah satu tempat penampungan air buangan atau limbah yang berasal dari berbagai kegiatan seperti perumahan penduduk, industry rumah tangga, dan pasar. Kota Padang terdapat beberapa sungai yang mengalir di sepanjang pemukiman penduduk di antaranya Sungai Batang Arau, Batang Kandis, Batang Kuranji dan lainnya. Oleh sebab itu kualitas sungai tersebut perlu dijaga agar masyarakat di sepanjang aliran sungai dapat memanfaatkannya.

Sungai Batang Kuranji secara administrasi berada pada 4 (empat) kecamatan yaitu kecamatan Pauh, Kuranji, Nanggalo, dan Padang Utara. Hulu dari sungai Batang Kuranji berada pada Kecamatan Pauh yaitu pada kelurahan Kapalo Koto dan bermuara pada Kecamatan Padang Utara yaitu pada Kelurahan Air Tawar Timur.

Secara geografis pertumbuhan penduduk kota Padang terutama pada keempat kecamatan yang dilalui oleh sungai Batang Kuranji akan berpengaruh terhadap kualitas sungai. Pengaruh tersebut karena setiap tahun angka laju pertumbuhan penduduk pada keempat kecamatan tersebut secara otomatis akan berdampak pada limbah cair yang dihasilkan.

Berdasarkan hasil pemantauan pada Sungai Batang Kuranji terdapat beberapa permasalahan yang dapat mengakibatkan perubahan kualitas air sungai di antaranya: 
Permasalahan yang ada di sepanjang aliran sungai Batang Kuranji adalah banyaknya terdapat permukiman penduduk, home industry seperti pabrik roti, warung nasi, catering, bengkel sepeda motor dan mobil, perguruan tinggi, dan pasar. Kegiatan tersebut menghasilkan limbah yang bermuara ke sungai Batang Kuranji sehingga dengan demikian potensi penurunan kualitas Sungai Batang Kuranji adalah sangat besar.

Ruang lingkup kajian terhadap kualitas air sungai Batang Kuranji adalah perhitungan debit air Sungai Batang Kuranji dan penentuan kualitas air sungai dengan peraturan Pemerintah Nomor 82 tahun 2001 tentang Pengelolaan Pencemaran dan Pengendalian Pencemaran Air. Peraturan tersebut berguna untuk membandingkan kualitas sungai Batang Kuranji dengan baku mutu lingkungan yang ditetapkan. Selanjutnya penentuan daya tampung sungai Batang Kuranji berpedoman pada Keputusan Menteri Lingkungan Hidup Nomor 110 tahun 2003 tentang Pedoman Penetapan Daya Tampung Beban Pencemaran Air pada Sumber Air.

Jenis penelitian ini adalah deskriptif kuantitatif yang menggambarkan kondisi wilayah studi dengan memanfaatkan data-data perimer dan sekunder yang telah dikumpulkan.Pengumpulan data pada penelitian kualitas Sungai Batang Kuranji baik data primer maupun data sekunder dimaksudkan agar mengetahui kondisi lingkungan awal di sepanjang aliran sungai Batang Kuranji saat dilakukan penelitian.Pada kajian kualitas air dan penentuan daya tampung sungai batang kuranji data primer diperoleh dari analisis laboratorium terhadap kualitas air sungai, observasi lapangan atas jumlah anak sungai, pola percabangan sungai, dan keadaan fisik di sepanjang aliran sungai batang kuranji.

Data primer yang diperlukan dalam kajian kualitas sungai batang kuranji padang, sebagai berikut; Parameter Kualitas Air, Kerapatan Daerah Aliran dan pola percabangan, Jumlah anak sungai yang bermuara di Sungai Batang 
Kuranji, Dasar Sungai / Keadaan Sungai, Debit rata-rata, Pola Sedimentasi, Keadaan Fisik Pinggir Sungai.

Data sekunder merupakan data yang diperoleh dari kajian literature, informasi dari instansi terkait, dan informasil dari pihak lain yang dapat dijadikan sebagai bahan masukan dalam penulisan laporan penelitian. Data sekunder diperlukan dalam penelitian sebagai penunjang dan melengkapi data primer yang telah ada. Beberapa data sekunder yang diperlukan di antaranya data keadaan geografis wilayah studi, kependudukan, tata guna lahan, batas administrasi. Lebih lengkap data sekunder yang diperlukan dalam kajian kualitas air sungai dan penentuan daya tampung sungai batang kuranji disajikan pada tabel 3.2.

Tabel 3.2 Data Sekunder Yang Diperlukan Pada Kajian Kualitas Sungai Batang Kuranji

\begin{tabular}{|l|l|l|l|}
\hline No & \multicolumn{1}{|c|}{$\begin{array}{c}\text { Data yang } \\
\text { diperlukan }\end{array}$} & \multicolumn{1}{|c|}{ Metode } & \multicolumn{1}{|c|}{ Instansi } \\
\hline 1 & Geografis & Studi dokumentasi & BPS \\
\hline 2 & Kependudukan & Studi dokumentasi & $\begin{array}{l}\text { BPS, kelurahan, dan } \\
\text { kecamatan }\end{array}$ \\
\hline 3 & Tata guna lahan & Studi dokumentasi & $\begin{array}{l}\text { Dinas Tata Ruang Kota } \\
\text { Padang }\end{array}$ \\
\hline 4 & $\begin{array}{l}\text { Batas administrasi } \\
\text { kajian }\end{array}$ & Studi dokumentasi & $\begin{array}{l}\text { BPS, kelurahan dan } \\
\text { kecamatan }\end{array}$ \\
\hline 5 & $\begin{array}{l}\text { Pola penutupan } \\
\text { vegetasi kajian }\end{array}$ & Studi dokumentasi & PSDA \\
\hline 6 & Prilaku banjir & Studi dokumentasi & PSDA \\
\hline 7 & $\begin{array}{l}\text { Kegiatan ekonomi } \\
\text { masyrakat }\end{array}$ & Studi dokumentasi & BPS, kelurahan \\
\hline
\end{tabular}

Lokasi penelitian dilakukan pada daerah sepanjang sungai batang kuranji yang mengalir pada empat kecamatan. Pengambilan sampel penelitian ditentukan berdasarkan daerah yang diasumsi mewakili berbagai 
kegiatan di sepanjang aliran sungai. Keterwakilan tersebut dipandang dalam segi kegiatan yang ada di sekitar sungai

\section{PEMBAHASAN}

\section{Gambaran Umum Lokasi Penelitian}

Kota padang terletak di pantai barat pulau sumatera yang secara geografis berada pada posisi $00^{\circ} 44^{\prime} 00^{\prime \prime}-10^{\circ} 10^{\prime} 35^{\prime \prime}$ Lintang Selatan dan $100^{\circ} 05^{\prime} 05^{\prime \prime}-100^{\circ} 05^{\prime} 05^{\prime \prime}$ Bujur Timur. Secara topografis kota Padang berada pada ketinggian 0 - 500 meter di atas permukaan laut (mdpl). Kota Padang mempunyai luas daerah $694,96 \mathrm{~km}^{2}$ setelah adanya perluasan kota pada tahun 1980 berdasarkan PP Nomor 17 tahun 1980 dengan jumlah penduduk pada tahun 2012 sebesar 784.740 jiwa dan laju pertumbuhan penduduk rata-rata $2,7 \%$ pertahun. Secara administrative kota Padang berbatasan dengan 3 kabupaten dan samudera hindia. Batasan daerah kota Padang adalah sebagai berikut:

Sebelah utara berbatasandengan Kabupaten Padang Pariaman

Sebelah selatan berbatasan dengan Kabupaten Pesisir Selatan

Sebelah timur berbatasan dengan Kabupaten Solok Selatan

Sebelah barat berbatasan dengan Samudera Hindia.

Sungai Batang Kuranji secara administrative berada di 4 (empat) kecamatan yaitu kecamatan Pauh, Kuranji, Nanggalo, dan Padang Utara. Ditinjau dari segi topografi keempat kecamatan yang dilalui oleh Sungai Batang Kuranji ini berada pada ketinggian 0-100 meter dari permukaan lain. Sungai Batang Kuranji memiliki panjang 17 km yang berhulu di Kelurahan Lambung Bukit dan Kapalo Kota kecamatan pauh serta bermuara ke Air Tawar Barat dan Ulak Karang Utara Kecamatan Padang Utara. Penggunaan lahan pada keempat kecamatan yang dilalui oleh sungai Batang Kuranji disajikan pada tabel 4.1 . 
Tabel 4.1 Luas Lahan Menurut Jenis Penggunaannya

\begin{tabular}{|l|l|l|l|l|l|}
\hline \multirow{2}{*}{ No } & \multicolumn{2}{|c|}{ Jenis Lahan } & \multicolumn{4}{c|}{ Luas Lahan, ha } \\
\cline { 3 - 6 } & & $\begin{array}{c}\text { Kec } \\
\text { Pauh }\end{array}$ & $\begin{array}{c}\text { Kec } \\
\text { Kuranj } \\
\text { i }\end{array}$ & $\begin{array}{c}\text { Kec } \\
\text { Nanggalo }\end{array}$ & $\begin{array}{c}\text { Kec } \\
\text { Padang } \\
\text { Utara }\end{array}$ \\
\hline 1 & Sawah & 1.095 & 2.112 & 254 & 15 \\
\hline 2 & Perkarangan/bangunan & 429 & 531 & 144 & 36 \\
\hline 3 & Kebun & 636 & - & 203 & - \\
\hline 4 & Lading & 219 & 931 & 86 & 9,5 \\
\hline 5 & Hutan Negara & 10.103 & 571 & - & - \\
\hline 6 & Hutan rakyat & 1.894 & 281 & - & 5 \\
\hline 7 & Sementara tidak diusahakan & - & 9 & 2 & 43 \\
\hline 8 & Lainnya & 252,10 & 1.306 & 118 & 695,5 \\
\hline
\end{tabular}

Sumber: BPS, Padang Dalam Angka, 2012

Kepadatan penduduk yang tertinggi dari empat kecamatan di sepanjang aliran Sungai Batang Kuranji adalah Padang Utara sebesar 9.125 jiwa $/ \mathrm{km}^{2}$ dan kepadatan yang terendah yaitu kecamatan Pauh sebesar 353 jiwa $/ \mathrm{km}^{2}$. Sedangkan bila dilihat dari banyaknya jumlah penduduk, maka kecamatan Kuranji memiliki jumlah penduduk yang terbanyak yaitu sebesar 113.976 jiwa dan jumlah penduduk yang terkecil kecamatan Pauh sebesar 51.354 jiwa.

\section{A. Identifikasi Sumber Pencemar}

Hasil identifikasi yang dilakukan di sepanjang alirang Sungai Batang Kuranji didapatkan limbah cair dihasilkan dari rumah tangga atau limbah domestic, aktivitas perindustrian seperti pabrik tahu, industry bata, industry nata de-coco, rumah makan, catering, bengkel, pencucian mobil dan motor, 
peternakan ayam, galian C, dan persawahan. Hasil survey lapangan terhadap jenis kegiatan yang berada di sepanjang aliran Sungai Batang Kuranji berpotensi mengakibatkan penurunan kualitas air sungai disajikan pada tabel 4.1

Sedangkan identifikasi pada sumber pencemar Sungai Batang Kuranji berdasarkan pada titik pengambilan dapat dilihat pada tabel dibawah ini :

Tabel 4.2. Identifikasi Sumber Pencemar yang Berpotensi Menurunkan Kualitas Air Sungai Batang Kuranji, Padang

\begin{tabular}{|c|c|c|c|}
\hline No & $\begin{array}{c}\text { Kecamatan } \\
\text { Kelurahan }\end{array}$ & Lahan Eksisting & $\begin{array}{c}\text { Identifikasi Sumber } \\
\text { Pencemar }\end{array}$ \\
\hline A. & Pauh & & \\
\hline 1 & Lambung Bukit & $\begin{array}{l}\text { Pertanian, peternakan, } \\
\text { pemukiman, industry }\end{array}$ & $\begin{array}{l}\text { Limbah cair dari pemukiman } \\
\text { penduduk, limbah cair } \\
\text { pertanian, limbah yang } \\
\text { berasal dari industry batu bata }\end{array}$ \\
\hline 2 & Kapalo Koto & $\begin{array}{l}\text { Pertanian, peternakan, } \\
\text { pemukiman }\end{array}$ & $\begin{array}{l}\text { Limbah cair dari pertanian, } \\
\text { peternakan, limbah cair yang } \\
\text { berasal dari pemukiman } \\
\text { penduduk, dan saluran } \\
\text { drainase yang masuk ke } \\
\text { sungai }\end{array}$ \\
\hline 3 & Cupak Tangah & $\begin{array}{l}\text { Pertanian, } \\
\text { pemukiman }\end{array}$ & $\begin{array}{l}\text { Limbah cair dari pemukiman } \\
\text { penduduk dan limbah } \\
\text { pertanian }\end{array}$ \\
\hline $\mathbf{B}$ & Kuranji & & \\
\hline 4 & Korong Gadang & $\begin{array}{l}\text { Pertanian, } \\
\text { pemukiman, industry, } \\
\text { perdagangan }\end{array}$ & $\begin{array}{l}\text { Limbah pertanian, limbah } \\
\text { pemukiman, galian } \mathrm{C} \text {, saluran } \\
\text { drainase yang masuk ke } \\
\text { sungai }\end{array}$ \\
\hline 5 & Kalumbuk & $\begin{array}{l}\text { Pertanian, peternakan, } \\
\text { pemukiman, industry, } \\
\text { perdagangan }\end{array}$ & $\begin{array}{l}\text { Limbah pertanian, industry } \\
\text { galian C, peternakan ayam, } \\
\text { limbah pemukiman dan } \\
\text { saluran drainase yang masuk } \\
\text { ke sungai }\end{array}$ \\
\hline 6 & Lubuk Lintah & $\begin{array}{l}\text { Pertanian, industry, } \\
\text { permukiman }\end{array}$ & $\begin{array}{l}\text { Limbah industry, } \text { galian C, } \\
\text { industry tahu, limbah } \\
\text { pemukiman, dan saluran }\end{array}$ \\
\hline
\end{tabular}




\begin{tabular}{|l|l|l|l|}
\hline C & Nanggalo & & drainase \\
\hline 7 & Kampung Olo & $\begin{array}{l}\text { Pertanian, industry, } \\
\text { perdagangan, } \\
\text { pemukiman }\end{array}$ & $\begin{array}{l}\text { Limbah pertanian, industry } \\
\text { roti, bengkel, pencucian } \\
\text { motor dan mobil, limbah } \\
\text { pemukiman penduduk }\end{array}$ \\
\hline 8 & Gurun Laweh & $\begin{array}{l}\text { Pertanian, } \\
\text { pemukiman }\end{array}$ & $\begin{array}{l}\text { Limbah yang berasal dari } \\
\text { pemukiman penduduk, } \\
\text { industry tahu, dan galian C, } \\
\text { output limbah PDAM }\end{array}$ \\
\hline 9 & Surau Gadang & $\begin{array}{l}\text { Pertanian, industry, } \\
\text { perdagangan, } \\
\text { pemukiman }\end{array}$ & $\begin{array}{l}\text { Limbah pemukiman } \\
\text { penduduk, industry nata de } \\
\text { coco, perdagangan, pencucian } \\
\text { motor dan pasar tradisional }\end{array}$ \\
\hline 10 & Kurao Pagang & Industry, pemukiman & $\begin{array}{l}\text { Limbah yang berasal dari } \\
\text { pemukiman, industry tahu }\end{array}$ \\
\hline D & Padang Utara & Pemukiman, & $\begin{array}{l}\text { Limbah yang berasal dari } \\
\text { pemukiman penduduk, dan } \\
\text { perbengkelan }\end{array}$ \\
\hline 11 & Air Tawar Barat & perdagangan & $\begin{array}{l}\text { Limbah yang berasal dari } \\
\text { pemukiman penduduk, } \\
\text { industry catering, rumah } \\
\text { makan dan perbengkelan }\end{array}$ \\
\hline 12 & Air Tawar Timur & $\begin{array}{l}\text { Pemukiman, } \\
\text { perdagangan, industrang }\end{array}$ \\
\hline
\end{tabular}

Sumber: Observasi Lapangan, tahun 2012

\section{Tabel 4.3 Identifikasi Sumber Pencemar pada Setiap Titik Pengambilan}

\section{Sampel}

\begin{tabular}{|l|l|l|l|}
\hline No & \multicolumn{1}{|c|}{ Lokasi } & Titik Koordinat & \multicolumn{1}{|c|}{$\begin{array}{c}\text { Identifikasi Sumber } \\
\text { Pencemar }\end{array}$} \\
\hline 1 & $\begin{array}{l}\text { Daerah hulu lambung } \\
\text { bukit, di atas } \\
\text { pemukiman penduduk } \\
\text { (sampel 1) }\end{array}$ & $\begin{array}{l}\text { S } 00.89903^{\circ} \\
\text { E } 100.46063^{\circ}\end{array}$ & $\begin{array}{l}\text { Limbah cair pemukiman, } \\
\text { pertanian, limbah yang } \\
\text { berasal dari industry batu bata }\end{array}$ \\
\hline 2 & $\begin{array}{l}\text { Pertemuan sungai limau } \\
\text { manis denagan sungai } \\
\text { batu busuak } \\
\text { (sampel 2) }\end{array}$ & $\begin{array}{l}\text { S } 00.92204^{\circ} \\
\text { E } 100.43908^{\circ}\end{array}$ & $\begin{array}{l}\text { Limbah cair dari pemukiman } \\
\text { penduduk dan limbah } \\
\text { pertanian }\end{array}$ \\
\hline 3 & $\begin{array}{l}\text { Pertemuan sungai } \\
\text { batang guo dengan } \\
\text { batang kuranji sebelum }\end{array}$ & $\begin{array}{l}\text { S } 00.89955^{\circ} \\
\text { E } 100.35608^{\circ}\end{array}$ & $\begin{array}{l}\text { Limbah pemukiman, } \\
\text { bengkel motor, galian C }\end{array}$ \\
\hline
\end{tabular}




\begin{tabular}{|c|c|c|c|}
\hline & $\begin{array}{l}\text { minang plaza } \\
\text { (sampel 3) }\end{array}$ & & \\
\hline 4 & $\begin{array}{l}\text { Setelah minang plaza } \\
\text { (sampel 4) }\end{array}$ & $\begin{array}{l}\text { S 00.90394 } \\
\text { E } 100.35078^{\circ}\end{array}$ & $\begin{array}{l}\text { Limbah pemukiman pasar } \\
\text { modern, perdagangan dan } \\
\text { bengkel }\end{array}$ \\
\hline 5 & $\begin{array}{l}\text { Dekat pintu air muaro, } \\
\text { bagian hilir } \\
\text { (sampel 5) }\end{array}$ & $\begin{array}{l}\text { S } 00.90565^{\circ} \\
\text { E } 100.34783^{\circ}\end{array}$ & $\begin{array}{l}\text { Limbah pemukiman } \\
\text { penduduk, perdagangan dan } \\
\text { bengkel }\end{array}$ \\
\hline
\end{tabular}

Sumber : hasil observasi lapangan, 2012

\section{B. Kualitas air Sungai}

\section{Kualitas Air Sungai Batang Kuranji}

Menurut peraturan Pemerintah No 82 tahun 2001 tentang pengelolaan kualitas air dan pengendalian pencemaran air menyatakan bahwa air diklasifikasikan berdasarkan 4 (empat) kelas yaitu:

Kelas I: diperuntukkan bagi kebutuhan air minum dan/atau peruntukkannya lain yang mempersyaratkan mutu air yang sama dengan kegunaan tersebut.

Kelas II: air yang peruntukkannya dapat untuk prasarana/sarana rekreasi air, pembudidayaan ikan air tawar, petrnakan, air untuk mengairi tanaman, dan/atau peruntukkanya lain yang mempersyaratkan mutu air yang sama dengan kegunaan tersebut.

Kelas III: digunakan untuk pembudidayaan ikan air tawar, peternakan, air untuk mengairi pertanaman dan/atau peruntukkannya lain yang mempersyaratkan mutu air yang sama dengan kegunaan tersebut.

Kelas IV: air digunakan untuk mengairi pertanaman dan/atau peruntukan lain yang mempersyaratkan mutu air yang sama dengan kegunaan tersebut. 
Hasil analisis laboratorium pada lokasi sampel 1 (satu), 2 (dua), 3 (tiga), 4 (empat) dan lokasi sampel 5 (Lima)disajikan pada tabel 4.4

Tabel 4.4 Hasil Analisis Kualitas Air Sungai Batang Kuranji Padang pada Lokasi 1, 2,

\begin{tabular}{|c|c|c|c|c|}
\hline \multirow[b]{2}{*}{ No } & \multirow[t]{2}{*}{ Parameter } & \multirow[t]{2}{*}{ satuan } & \multicolumn{2}{|c|}{ Lokasi Sampel } \\
\hline & & & $\mathbf{1}$ & 2 \\
\hline $\mathbf{I}$ & FISIKA & & & \\
\hline 1 & Temperature & ${ }^{\circ} \mathrm{C}$ & & \\
\hline 2 & Pedat terlarut (TDS) & $\mathrm{Mg} / \mathrm{L}$ & 70 & 100 \\
\hline 3 & Padat tersuspensi (TSS) & $\mathrm{Mg} / \mathrm{L}$ & 30 & 90 \\
\hline II & $\begin{array}{l}\text { KIMIA } \\
\text { ANORGANIK }\end{array}$ & & & \\
\hline 1 & $\mathrm{Ph}$ & - & 7 & 7 \\
\hline 2 & $\mathrm{BOD}$ & $\mathrm{Mg} / \mathrm{L}$ & 2 & 6 \\
\hline 3 & COD & $\mathrm{Mg} / \mathrm{L}$ & 6,8 & 17 \\
\hline 4 & DO & $\mathrm{Mg} / \mathrm{L}$ & 9 & 7 \\
\hline 5 & Posfat (Po4-P) & $\mathrm{Mg} / \mathrm{L}$ & ttd & Ttd \\
\hline 6 & Tembaga & $\mathrm{Mg} / \mathrm{L}$ & ttd & Ttd \\
\hline 7 & Besi (fe) & $\mathrm{Mg} / \mathrm{L}$ & 0,2 & 13,2 \\
\hline 8 & Sulfat $\left(\mathrm{SO}_{4}\right)$ & $\mathrm{Mg} / \mathrm{L}$ & 7 & 21 \\
\hline 9 & Belerang $\left(\mathrm{H}_{2} \mathrm{~S}\right)$ & $\mathrm{Mg} / \mathrm{L}$ & ttd & Ttd \\
\hline III & KIMIA ORGANIK & & & \\
\hline 1. & Minyak/lemak & $\mathrm{Mg} / \mathrm{L}$ & $\mathrm{ttd}$ & $\mathrm{ttd}$ \\
\hline 2. & Detergen, MBAS & $\mathrm{Mg} / \mathrm{L}$ & ttd & $\mathrm{ttd}$ \\
\hline 3. & Fenol & $\mathrm{Mg} / \mathrm{L}$ & - & \\
\hline IV & MIKROBIOLOGI & & & \\
\hline 1. & Total coliform & $\mathrm{Jml} / 100$ & $>2400$ & $>2400$ \\
\hline
\end{tabular}

Sumber : hasil analisis laboratorium, 2012

Ket:

1 : hulu sungai di atas pemukiman pendudukan, kelurahan lambung bukit

2 : pertemuan sungai limau manis dan sungai batu busuak 
Tabel 4.5 Hasil Analisis Kualitas Air Sungai Batang Kuranji Padang pada Lokasi 3,4,5

\begin{tabular}{|c|c|c|c|c|c|}
\hline \multirow[b]{2}{*}{ No } & \multirow[t]{2}{*}{ Parameter } & \multirow[t]{2}{*}{ satuan } & \multicolumn{3}{|c|}{ Lokasi Sampel } \\
\hline & & & 3 & 4 & 5 \\
\hline I & FISIKA & & & & \\
\hline 1 & Temperature & ${ }^{\circ} \mathrm{C}$ & & & \\
\hline 2 & Pedat terlarut (TDS) & $\mathrm{Mg} / \mathrm{L}$ & 715 & 890 & 2.130 \\
\hline 3 & Padat tersuspensi (TSS) & $\mathrm{Mg} / \mathrm{L}$ & 311 & 480 & 1.450 \\
\hline II & $\begin{array}{l}\text { KIMIA } \\
\text { ANORGANIK }\end{array}$ & & & & \\
\hline 1 & $\mathrm{pH}$ & - & 6,8 & 6,8 & 6,8 \\
\hline 2 & BOD & $\mathrm{Mg} / \mathrm{L}$ & 40 & 57 & 64 \\
\hline 3 & $\mathrm{COD}$ & $\mathrm{Mg} / \mathrm{L}$ & 105,8 & 161 & 197,6 \\
\hline 4 & DO & $\mathrm{Mg} / \mathrm{L}$ & 6,5 & 5,7 & 5,2 \\
\hline 5 & Posfat (Po4-P) & $\mathrm{Mg} / \mathrm{L}$ & 0,009 & 0,025 & 0,079 \\
\hline 6 & Tembaga & $\mathrm{Mg} / \mathrm{L}$ & $\operatorname{Ttd}$ & 0,003 & 0,003 \\
\hline 7 & Besi (fe) & $\mathrm{Mg} / \mathrm{L}$ & 10,9 & 7,1 & 18,6 \\
\hline 8 & Sulfat $\left(\mathrm{SO}_{4}\right)$ & $\mathrm{Mg} / \mathrm{L}$ & 420 & 1681 & 1315 \\
\hline 9 & Belerang $\left(\mathrm{H}_{2} \mathrm{~S}\right)$ & $\mathrm{Mg} / \mathrm{L}$ & 0,124 & 0,148 & 0,149 \\
\hline III & KIMIA ORGANIK & & & & \\
\hline 1. & Minyak/lemak & $\mathrm{Mg} / \mathrm{L}$ & Ttd & 0,15 & 0,4 \\
\hline 2. & Detergen, MBAS & $\mathrm{Mg} / \mathrm{L}$ & 8,7 & 8,5 & 9,1 \\
\hline 3. & Fenol & $\mathrm{Mg} / \mathrm{L}$ & - & - & \\
\hline IV & MIKROBIOLOGI & & & & \\
\hline 1. & Total coliform & $\mathrm{Jml} / 100$ & $>2400$ & $>2400$ & $>2400$ \\
\hline
\end{tabular}

Sumber : hasil analisis laboratorium, 2012

Ket:

1 : Pertemuan Sungai Batang Guo dengan Batang Kuranji

2 : Setelah Minang Plaza

3 : dekat pintu air Muaro

\section{Daya Tampung Sungai Batang Kuranji}

Daya tampung beban pencemaran air menurut Kepmen LH No 110 tahun 2003 adalah kemampuan air pada suatu sumber air, untuk dapat menerima masukan beban pencemaran tanpa mengakibatkan air tersebut 
cemar. Beban pencemaran adalah jumlah suatu unsure yang terkandung dalam air atau air limbah. Penentuan daya tampung Sungai Batang Kuranji dilaksanakan berpedoman pada hasil pemeriksaan laboratorium yang telah dilakukan dan penetapan kelas pemeriksaan laboratorium yang telah dilakukan dan penetapan kelas air pada setia daerah di Sungai Batang Kuranji.

Parameter yang akan dilakukan pengkajian pada Sungai Batang Kuranji adalah parameter kunci yang berpotensi mengakibatkan penurunan kualitas air sungai. Potensi pencemaran Sungai Batang Kuranji Berdasarkan observasi lapangan yang dilakukan berasal dari aktivitas pemukiman penduduk/limbah rumah tangga, limbah pertanian, peternakan, industry rumah tangga yang menghasilkan parameter organic, perdagangan, dan jasa. Parameter tersebut yaitu BOD dan COD. Pertimbangan analisa yang dilakukan pada keempat parameter tersebut karena di sepanjang aliran Sungai Batang Kuranji tidak terdapat industry yang mengeluarkan limbah cair berupa logam berat.

Perhitungan daya tampung yang dilakukan pada sungai Batang Kuranji dibagi 5 (lima) bagian perhitungan. Pertimbangan ini berdasarkan atas jenis yang sama, sumber pencemar yang mengakibatkan penurunan kualitas air Sungai Batang Kuranji, adanya anak sungai yang masuk dan keluar dari Sungai Batang Kuranji. Kelima daerah tersebut yaitu:

Bagian 1 (satu) meliputi bagian hulu lambung bukit sampai pertemuan sungai limau manis.

Bagian 2 (dua) yaitu dimulai pada pertemuan Sungai Batang Kuranji sampai dengan jembatan kalumbuk.

Bagian 3 (tiga) yaitu setelah jembatan kalumbuk sampai dengan setelah jembatan Pasar Siteba.

Bagian 4 (emat) yaitu meliputi setelah pasar Siteba sampai dengan pertemuan Sungai Batang Guo. 
Bagian 5 (lima) dimulai dari Sungai Batang Guo dan Kuranji sampai dengan hilir yaitu Kelurahan Air Tawar Barat.

\section{Rencana Pengelolaan Sungai Batang Kuranji}

Sebagaimana diketahui bahwa air merupakan di antara kebutuhan hidup yang paling penting. Selain itu air adalah sumber daya alam yang dapat diperbaharui dengan kuantitasnya di dunia tetap, persediaannya tidak dapat ditambah atau ditingkatkan dan juga tidak dapat dikurangi melalui langkah dan upaya apapun.

Namun saat ini permasalahan penggunaan air yang muncul yaitu makin buruknya kualitas air yang diperoleh. Semakin banyaknya limbah domestic, limbah industry rumah tangga seperti industry tahu, pabrik roti, kateringg dan limbah industry rumah makan yang masuk ke air permukaan menyebabkan penurunan kualitas air permukaan. Oleh sebab itu diperlukan langkah agar kualitas air permukaan tidak menurun sehingga dapat digunakan untuk menunjang aktivitas manusia.

\section{PENUTUP}

1. Menjaga debit sungai Batang Kuranji dengan jalan memelihara dan melakukan konservasi tanaman di sepanjang aliran Sungai Batang Kuranji.

2. Mempertahankan vegetasi yang telah ada di sepanjang aliran Sungai Batang Kuranji terutama untuk kawasan hulu.

3. Membatasi pemukiman penduduk lebih kurang 50 meter di sisi kiri dan kanan di sepanjang Sungai Batang Kuranji.

4. Pembuatan Instalasi Pengolahan Air Limbah (IPAL) di pemukiman penduduk sebelum masuk ke sungai Batang Kuranji.

5. Instalasi Pengolahan Air Limbah untuk industry rumah tangga yang ada di sepanjang aliran sungai Batang Kuranji harus berfungsi dengan baik. 


\section{DAFTAR PUSTAKA}

Asdak, Chay. 2004. Hidrologi dan Pengelolaan Daerah Aliran Sungai. Gajah Mada University Press. Yogyakarta.

Biro Pusat Statistik, 2011 "Pauh Dalam Angka", BPS Kota Padang

Biro Pusat Statistik, 2011 "Kuranji Dalam Angka”, BPS Kota Padang

Biro Pusat Statistik, 2011 "Nanggalo Dalam Angka”, BPS Kota Padang

Biro Pusat Statistik, 2011 "Padang Utara Dalam Angka”, BPS Kota Padang

Ediyono, Setijadi H; Yusuf, Macftuchah; Hendrawan Dianan I; Nuroho Astri

R. 2003. Prinsip-prinsip Lingkunan dalam Pembangunan yang

Berkelanjutan. CV Idayus dan LPKLP Universitas Trisakti,

Dirjen Dikti. Jakarta

Faridaz, Srikandi. 1992. Polusi Air dan Udara. Kanisius. Jakarta

PUSARPEDAL/EMC Deputi VII-KLH. 2006. Pedoman umum pemantauan kualitas air. JICA. Jakarta

Keputusan Menteri Lingkungan Hidup Nomor 110 Tahun 2003 tentang Pedoman Penetapan Daya Tampung Beban Pencemaran Air pada Sumber Air

Peraturan Pemerintah Nomor 82 Tahun 2001 tentang Pengelolaan dan Kualitas Air dan Pengendalian Pencemaran Air.

Prasetyo, Bambang; Jannah, Lina M. 2006. Metode Penelitian Kuantitatif. PT. Raja Grafindo Persada. Jakarta

Salim, Emil, (1983), "Lingkungan Hidup dan Pembangunan", Mutiara, Jakarta

Sastrawijaya, Tresna. 2000. Pencemaran Lingkungan. Rineka Cipta. Jakarta

Widyastuti, M, Marfai Muh A. 2004. Kajian Daya Tampung Sungai Gajahwong terhadap Beban Pencemaran. Fakultas Geografi. Universitas Gaja Mada. 